\title{
Utilização de bioensaios e marcadores moleculares para detecção da resistência de coleópteros de produtos armazenados a inseticidas ${ }^{1}$
}

\author{
Fabiane Cristina Ceruti ${ }^{2}$ \\ Sonia Maria Noemberg Lázzari²
}

\begin{abstract}
Aвstract. Use of bioassays and molecular markers to detect insecticide resistance in stored products beetles. The qualitative and quantitative losses caused by stored product insects are of great concern, and since there is only a few active ingredients available for their control it is very important to have a frequent insect resistance monitoring. The objective of this research is to evaluate combination of bioassays and molecular marker techniques to detect insecticide resistance in stored product beetles. The Coleoptera species used for the tests were Sitophilus oryzae (L.) (Curculionidae), Rhyzopertha dominica (F.) (Bostrichidae) and Oryzaephilus surinamensis (L.) (Silvanidae). For the bioassays it was used the impregnated filter paper technique, applying $1 \mathrm{~mL}$ of deltamethrin (K-Obiol $25 \mathrm{CE}^{\mathrm{TM}}$ ) using four concentrations and five replicates, including a control with solvent only. Ten adults of each species were liberated separately on each dish. The mortality was evaluated after $24 \mathrm{~h}$ and resistance determined by probit analysis. The samples used for the PCR-RAPD were either in vivo or preserved in $70 \%$ ethanol, kept in $-18^{\circ} \mathrm{C}$ freezer. After extraction, quantification and DNA quality analysis, the $25 \mu \mathrm{L}$ samples had the DNA amplified and tested with six primers. The bioassays showed a crescent mortality proportional to insecticide concentration. The resistance factor for $R$. dominica, S. zeamais and S. oryzae were: 2,2; 3,2 and 9,2, respectively, compared to the susceptible populations of each species. The PCR-RAPD analysis revealed bands which indicate inter and intraspecific variability in the populations, but it was not possible to correlate them to resistance. The association of bioassay and PCR-RAPD represents a precise and valuable tool for resistance management of stored product insects, but more populations and primers should be tested.
\end{abstract}

KEYwords. Coleoptera; deltamethrin; insecticide resistance; PCR-RAPD markers; stored product insects.

\section{INTRODUÇÃO}

Resistência é a habilidade de indivíduos de uma espécie de suportar doses de substâncias tóxicas que seriam letais para a maioria dos indivíduos da população normal (SUBRAMANYAM \& HagstRum 1996). O termo resistência é aplicado por SмIтH (1970) para caracterizar espécies de insetos anteriormente suscetíveis cuja população não pode mais ser controlada por um dado inseticida na dose normalmente recomendada ou em nenhuma dose. A resistência deve ser vista como um fenômeno de préadaptação, isto é, o inseticida não induz as mudanças hereditárias mas somente seleciona, em cada geração, os genes responsáveis pela resistência, encontrados em uns poucos indivíduos (BROwn 1958).

Segundo GEORGHIOU (1972), os insetos apresentam diversos mecanismos de resistência: bioquímicos, fisiológicos e comportamentais. A detoxificação realizada por enzimas é um dos mais importantes; os inseticidas organofosforados, carbamatos e piretróides são detoxificados pela ação de oxidases de funções mistas, esterases e transferases; os organofosforados sofrem também a ação de hidrolases. Os mecanismos fisiológicos incluem a redução da penetração e transporte do inseticida para o alvo (sistema nervoso), insensibilidade do sítio de ação e aumento da excreção. O autor refere-se, ainda, à resistência comportamental devida a efeitos irritantes e repelentes dos inseticidas sobre indivíduos fisiologicamente suscetíveis, os quais alteram seu comportamento para evitar áreas tratadas.

Em algumas espécies de coleópteros de produtos armazenados houve comprovação da resistência bioquímica, como indicado por SuBRAMANYAM et al. (1989) que detectaram, nos Estados Unidos, resistência ao malation em todas as

1. Contribuição $n^{\circ} 1380$ do Departamento de Zoologia, Universidade Federal do Paraná.

2. Departamento de Zoologia, UFPR. Caixa Postal 19020, 81531-980 Curitiba-PR, Brasil.

Endereço eletrônico: lazzari@ufpr.br; biaceruti@bio.ufpr.br 
linhagens de campo de Tribolium castaneum (Herbst, 1797) (Coleoptera, Tenebrionidae) testadas, estando as carboxilesterases envolvidas com a detoxificacão do produto. Collins et al. (1992), trabalhando com quatro linhagens de Oryzaephilus surinamensis (Linnaeus, 1758) (Coleoptera, Silvanidae), constataram diferentes níveis de resistência ao fenitrotion, associada à alta atividade de monoxigenase, e ao clorpirifós-metil, à alta atividade de esterases.

GUEDEs et al. (1997) demonstraram que a atividade específica de acetilcolinesterase diferiu significativamente entre populações brasileiras resistentes e suscetíveis de Rhyzopertha dominica (Fabricius, 1792) (Coleoptera, Bostrichidae) indicando que a atividade aumentada da acetilcolinesterase estaria associada com a resistência a organofosforados. Com relação à resistência bioquímica aos piretróides, estudos de Coluins (1990), com T. castaneum, indicam que o aumento do metabolismo enzimático na molécula do inseticida envolveu oxidação e/ou hidrólise por ésteres.

No Brasil, há indicação de resistência de Sitophilus oryzae (Linnaeus, 1763) (Coleoptera, Curculionidae) e T. castaneum a organofosforados (PACHECO et al. 1991) e à fosfina (SARTORI et al. 1991). GuEdes (1993) registrou a resistência de linhagens de Sitophilus zeamais Motschulsky, 1855 a DDT e piretróides. Bioensaios combinando inseticidas com sinergistas sugerem o envolvimento de esterases no mecanismo de resistência de S. zeamais à cipermetrina (RIBEIRo et al. 2003). A estabilidade e severidade da resistência têm sido documentadas para algumas linhagens das principais espécies de insetos de armazenamento a inseticidas, em diversas regiões do País. Isso evidencia a necessidade urgente de fazer o manejo integrado de pragas no armazenamento (LoRINI 1998) para que esses inseticidas sejam preservados pelo maior tempo possível, haja vista a grande dificuldade de substituição desses produtos.

A importância do estudo da resistência de insetos de produtos armazenados a inseticidas pode ser resumida em dois aspectos: o primeiro refere-se às perdas quantitativas e qualitativas da produção impostas pelo ataque de insetos; o segundo está relacionado com o reduzido número de produtos utilizados no controle desses insetos, sendo que, uma vez estabelecida a resistência, pouco poderá ser feito para efetuar um controle efetivo das populações.

O manejo da resistência tem como objetivos: prevenir, retardar ou reverter a evolução da resistência de pragas aos inseticidas. A detecção e estimativa da resistência e de padrões genéticos da resistência, bem como o desenvolvimento de técnicas rápidas, simples e confiáveis, são essenciais para desenvolver um programa bem sucedido de manejo da resistência. A estratégia mais comum tem sido o uso de diversos inseticidas usados seqüencialmente, em misturas ou rotação (Roush 1989; TABASHNIK 1989), além de produtos sinérgicos que bloqueiam certos processos metabólicos. O desenvolvimento da resistência pode ser retardado ao reduzirse o número de aplicações de inseticidas, adequando as dosagens de acordo com a freqüência da resistência e uso de produtos menos persistentes. A suscetibilidade pode ser preservada provendo refúgio para esses indivíduos, através de coberturas parciais, propiciando a imigração dos suscetíveis para a diluição dos genes resistentes.

O conhecimento da base genética da resistência a inseticidas é fundamental para estabelecer estratégias para o manejo da resistência. Maiores progressos no entendimento da resistência poderiam ser obtidos se houvesse disponibilidade de marcadores moleculares ligados à resistência. Diversas técnicas para a obtenção de marcadores moleculares (DNA) foram desenvolvidas e já estão sendo utilizadas em entomologia. Um avanço importante para a disseminação do uso de marcadores moleculares foi o estabelecimento da técnica PCR (Polymerase Chain Reaction - Reação em Cadeia da Polimerase). Através dela é possível ampliar exponencialmente um fragmento específico de DNA a partir de uma quantidade muito pequena de moléculas.

Um dos protocolos de amplificação de DNA derivado de PCR é o RAPD (Random Amplified Polymorphic DNA Amplificação ao Acaso de DNA Polimórfico), o qual permite a ampliação de fragmentos de DNA delimitados por primers (10 pares de bases) com seqüências arbitrárias, os quais hibridizamse em seqüências complementares distribuídas ao acaso no DNA. Desta forma, são detectadas variações produzidas por

Tabela I. Populações de coleópteros de produtos armazenados utilizados nos bioensaios e em testes com marcadores moleculares (DNA), indicando o método de preservação das amostras para PCR-RAPD, visando a avaliação da resistência à deltametrina.

\begin{tabular}{lll}
\hline População & Origem & Método de preservação \\
\hline Sitophilus zeamais & Viçosa, MG & In vivo \\
Sitophilus zeamais & Campo-Erê, SC & In vivo \\
Sitophilus zeamais & Videira, SC & In vivo \\
Sitophilus zeamais & Guarapuava, PR & In vivo \\
Rhyzopertha dominica (BR4 - suscetível) & Passo Fundo, RS & In vivo/ etanol $70 \%$ \\
Rhyzopertha dominica (BR12 - resistente) & Passo Fundo, RS & In vivo/ etanol $70 \%$ \\
Sitophilus oryzae A & Laboratório (trigo) & Congelados $-18^{\circ} \mathrm{C}$ \\
Sitophilus oryzae B & Laboratório (trigo) & Congelados $-18^{\circ} \mathrm{C}$ \\
Oryzaephilus surinamensis & Passo Fundo, RS & Etanol $70 \%$ \\
\hline
\end{tabular}


mutações nos sítios de hibridização ou por inserções e deleções entre esses sítios.

A escolha do uso da técnica de RAPD, dentre outras capazes de fornecer marcadores, deve-se a algumas vantagens como a não necessidade de ter informação prévia sobre seqüências de DNA, grande disponibilidade de primers, rapidez e custo mais baixo que outras técnicas de PCR. Algumas desvantagens também podem ser enumeradas: marcadores dominantes, falta de reprodutibilidade se as condições da reação não forem otimizadas ou se problemas de contaminação não forem resolvidos. Entretanto, com a atenção devida a estas restrições, RAPD pode fornecer bastante informação, especialmente em espécies que ainda não foram sujeitas a análises genéticas detalhadas, devido ao grande número de marcadores que pode ser obtido.

Para encontrar marcadores moleculares adequados para a resistência a inseticidas, podem ser comparados perfis de RAPD de grupos de insetos suscetíveis e resistentes, preferencialmente obtidos da mesma população. Isto diminui o número de fragmentos que são devidos às diferenças entre populações e que, portanto, não estariam relacionados à resposta aos inseticidas. Portanto, bandas que são grupoespecíficas são candidatas para análise de ligação gênica usando cruzamentos entre insetos suscetíveis e resistentes.

Este trabalho teve como objetivos detectar, através de bioensaios, populações de coleópteros resistentes à deltametrina e, na seqüência, identificar e/ou confirmar a resistência das populações através de marcadores moleculares a fim de avaliar a combinação dessas duas técnicas como um instrumento para o monitoramento da resistência de insetos de armazenamento.

\section{MATERIAL E MÉTODOS}

Foram coletadas amostras de insetos de produtos armazenados em armazéns no Sul do Brasil e em Minas Gerais, incluindo as seguintes espécies: $S$. zeamais, $S$. oryzae, $R$. dominica e $O$. surinamensis, que são as principais pragas de grãos e farinhas (Tabela I).

Cada espécie, de cada local, foi criada sobre o grão/produto de origem, em um frasco plástico de $2 \mathrm{~L}$, com tampa de tela fina. Os grãos foram previamente congelados para eliminar qualquer infestação. A criação foi mantida em câmara climatizada a $25^{\circ} \mathrm{C}$ e umidade relativa de $75 \%$. As amostras eram repicadas periodicamente para a manutenção das populações.

\section{Bioensaios}

Foi utilizada a técnica de tratamento de papel de filtro impregnado com inseticida (FAO Método $n^{\circ} 15$ ). Os discos de papel de filtro com $9 \mathrm{~cm}$ de diâmetro foram tratados com $1 \mathrm{~mL}$ de solução de deltametrina em diferentes concentrações, usando acetona como solvente, sendo o controle tratado somente com acetona (FAO 1974).

Foram testadas quatro concentrações do inseticida deltametrina (K-Obiol $25 \mathrm{CE}^{\circledR}$ ), com 5 repetições, iniciando-se com a dosagem recomendada pelo fabricante $(25 \mathrm{~g} / 1000 \mathrm{~mL})$ que foi então dividida pela metade e assim, sucessivamente, o limite das concentrações foi de $0,125 \%$ a $2 \%$. Cada papel, com as respectivas concentrações do inseticida, foi seco ao ar e colocado em uma placa de Petri. Após 1 h, foram colocados em cada placa 10 adultos da espécie em questão, não sexados e sem idade definida, fechando-se as placas com fita adesiva para evitar a fuga. Os insetos permaneceram expostos aos tratamentos durante 24 h, quando, então, a mortalidade foi avaliada, anotando-se o número de insetos mortos, expresso em porcentagem. Eram considerados mortos os insetos que, em 1 minuto, não conseguiram desvirar-se quando colocados de costas. A $\mathrm{CL}_{50}$ foi estimada através da análise de Probit, pelo programa GLIM, Royal Statistical Society versão 3.77 (CRAWLey 1993). O fator de resistência (FR) foi obtido pela razão entre a $\mathrm{CL}_{50}$ da população mais resistente e a $\mathrm{CL}_{50}$ da população suscetível de cada espécie estudada.

\section{Marcadores moleculares}

As amostras submetidas à técnica de PCR-RAPD foram preservadas em etanol a $70 \%$, congeladas a $-18^{\circ} \mathrm{C}$ e algumas in

Tabela II. Valores da $\mathrm{CL}_{50}\left(\mu \mathrm{g} / \mathrm{cm}^{2}\right.$ de deltametrina) para adultos de Sitophilus zeamais, S. oryzae, Rhyzopertha dominica e Oryzaephilus surinamensis expostos a papel filtro tratado com deltametrina para a determinação do fator de resistência, a $25^{\circ} \mathrm{C}$ e $70 \%$ UR, Curitiba, PR, 2000.

\begin{tabular}{lcccccc}
\hline População & $\mathbf{C L}_{\mathbf{5 0}} \mathbf{( 9 5 \% ~ I . C . )}^{*}$ & $\mathbf{a}$ & $\mathbf{E P}_{\mathbf{a}}$ & $\mathbf{B}$ & $\mathbf{E P}_{\mathbf{b}}$ & $\mathbf{F R}$ \\
\hline S. zeamais (Viçosa, MG) & $0,5467(0,4261-0,7584)$ & 0,7606 & 0,2551 & 2,900 & 0,5178 & 3,22 \\
S. zeamais (Campo-Erê, SC) & $0,5222(0,4025-0,7329)$ & 0,7714 & 0,2543 & 2,734 & 0,5043 & 3,07 \\
S. zeamais (Videira, SC) & $0,2264(0,1558-0,2971)$ & 1,685 & 0,2998 & 2,611 & 0,500 & 1,34 \\
S. zeamais (Guarapuava, PR) & $0,1698(0,0798-0,2479)$ & 1,472 & 0,2862 & 1,911 & 0,4750 & - \\
S. oryzae A & $1,209(1,129-1,269)$ & $-1,322$ & 0,3556 & 16,07 & 0,2671 & 9,2 \\
S. oryzae B & $0,1315(0,0675-0,1856)$ & 2,186 & 0,3480 & 2,481 & 0,5398 & - \\
R. dominica (BR12) & $0,4883(0,3235-0,6596)$ & 0,7161 & 0,1784 & 2,30 & 0,4791 & 2,2 \\
R. dominica(BR4) & $0,2212(0,1404-0,3005)$ & 1,489 & 0,2864 & 2,272 & 0,4818 & - \\
O. surinamensis & $0,1966(0,1314-0,2581)$ & 1,906 & 0,3179 & 2,699 & 0,5156 & - \\
\hline
\end{tabular}

*Concentração letal $50 \%\left(\mathrm{CL}_{50}\right)$ e intervalo de confiança (I.C.)

$\mathrm{a}=$ coeficiente linear; $\mathrm{b}=$ coeficiente angular; $\mathrm{EP}=$ Erro Padrão; FR = Fator de Resistência 

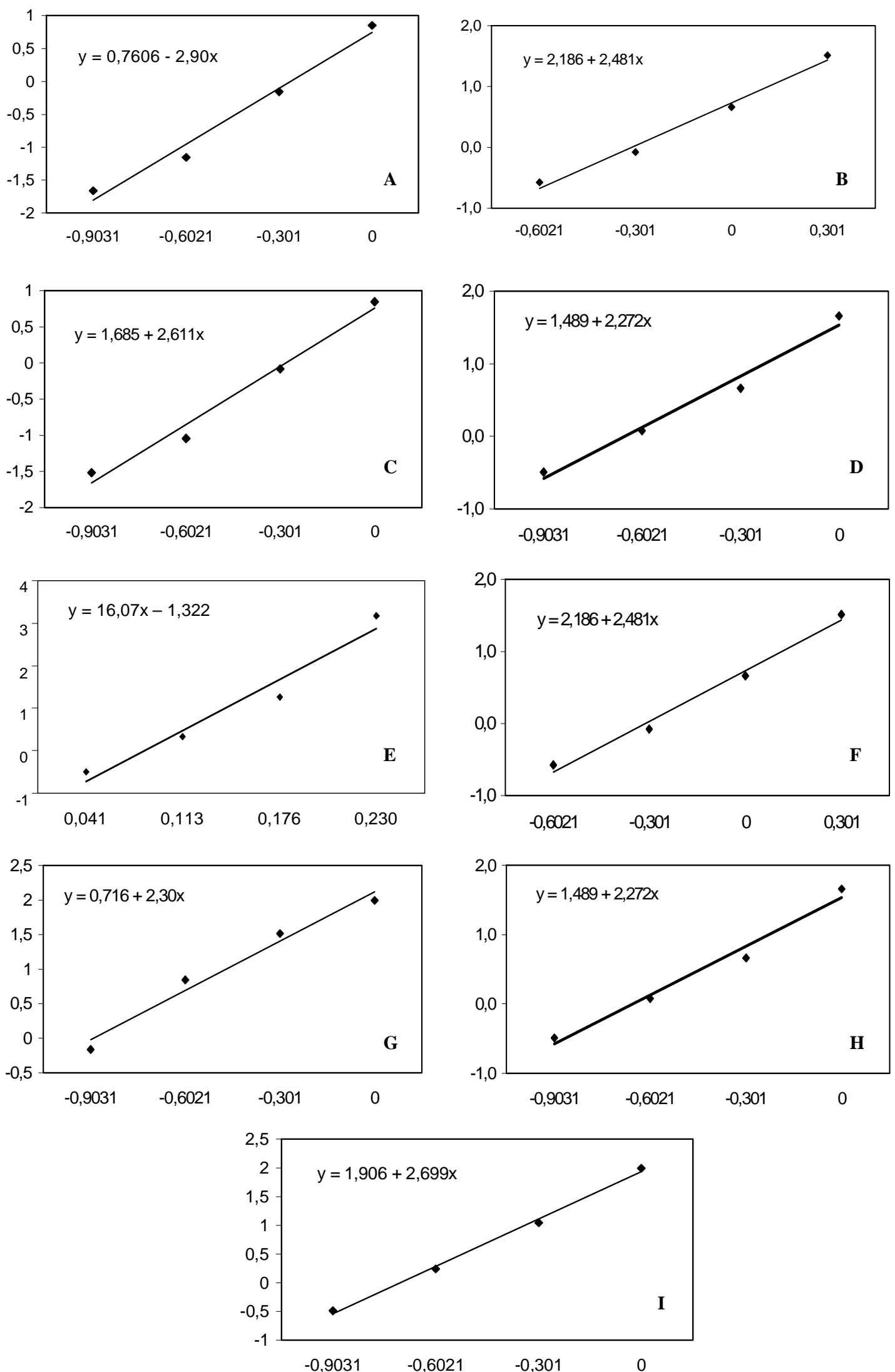

Fig. 1. Mortalidade de adultos de insetos submetidos a diferentes concentrações de deltametrina $\left(\mu \mathrm{g} / \mathrm{cm}^{2}\right)$ em papel filtro impregnado, em 5 repetições, a $25{ }^{\circ} \mathrm{C}$ e $70 \%$ UR, Curitiba, PR, 2000. A- Sitophilus zeamais, Viçosa-MG; B- S. zeamais, Campo-Erê-SC; C- S. zeamais, Videira-SC; DS. zeamais, Guarapuava-PR; E- Sitophilus oryzae, população A; F- S. oryzae, população B; G- Rhyzopertha dominica, BR12; H- R. dominica, BR4; I- Oryzaephilus surinamensis. 
vivo para verificação da interferência do método de preservação na qualidade das bandas.

Foi usado o protocolo de extração de DNA total descrito por Cheung et al. (1993). A quantificação do DNA foi determinada através da coloração da amostra com o corante Hoeschst 33258 e examinada em fluorímetro. A qualidade do DNA foi determinada através de eletroforese em gel de agarose a 0,8\%, utilizando-se 500 ng de DNA para cada amostra. A corrida foi em 0,5 X TBE (Tris-borato-EDTA) a $5 \mathrm{~V} / \mathrm{cm}$, corandose o gel em solução de brometo de etídio 0,05\%. O marcador utilizado foi o $\mathrm{n}^{\circ} 6$ da Pharmacia Biotech com 23.130 pares de bases (pb). Cada amostra apresentava um volume final de 20 mL contendo DNA + Bromofenol blue $+\mathrm{H}_{2} \mathrm{O}$ Milli Q. O gel foi fotografado com o sistema Kodak EDAS 120.

As reações de amplificação (PCR-RAPD) foram realizadas seguindo uma metodologia previamente testada para outros insetos no Instituto Ambiental do Paraná (IAPAR) de Londrina. Usou-se um volume total de $25 \mathrm{~mL}$ em tubos de microcentrífuga de $0,5 \mathrm{~mL}$, contendo $100 \mu \mathrm{M}$ de dATP, dCTP, dGTP e dTTP, 0,5 $\mu \mathrm{M}$ de cada primer, $25 \mathrm{ng}$ de DNA, 1,25 U de Taq polimerase, 0,05\% de BSA e tampão (10 mM Tris-HCl, 3 mM MgCl e 50 $\mathrm{mM} \mathrm{KCl}, \mathrm{pH}$ 8,3). As amplificações foram conduzidas em ciclador térmico (M.J. Research), com período inicial de desnaturação 3 min a $94{ }^{\circ} \mathrm{C}, 3 \mathrm{~min}$ a $35^{\circ} \mathrm{C}$ e $2 \min$ a $72^{\circ} \mathrm{C}$, seguidos de 40 ciclos de $1 \mathrm{~min}$ a $94^{\circ} \mathrm{C}, 1 \mathrm{~min}$ a $36^{\circ} \mathrm{C}$ e
2 min a $72{ }^{\circ} \mathrm{C}$, com extensão final de 5 min a $72{ }^{\circ} \mathrm{C}$. Foram utilizados os primers OPA-05, OPA-07, OPA-10, OPA-16, OPA18 e OPA-20. Os produtos das amplificações foram visualizados através da eletroforese usando $15 \mu \mathrm{L}$ da reação em $1,2 \%$ gel de agarose, a $5 \mathrm{~V} / \mathrm{cm}$, contendo $0,5 \mathrm{mg} / \mathrm{mL}$ de brometo de etídio, e em seguida fotografados com o sistema de análise de imagens Kodak EDAS 120.

\section{RESULTADOS E DISCUSSÃO}

\section{Bioensaios com deltametrina}

Os resultados dos bioensaios mostraram, para S. zeamais (Tabela II), que as populações de Viçosa-MG (Fig. 1A) e de Campo-Erê-SC (Fig. 1B), com CL ${ }_{50}$ 0,5467 e 0,5222, respectivamente, foram mais resistentes que as populações de Videira-SC (Fig. 1C) e Guarapuava-PR (Fig. 1D), com CL Ce $_{50}$ de 0,2264 e 0,1698, respectivamente. O FR das três primeiras populações com relação à de Guarapuava, considerada a mais suscetível, foi 3,22; 3,07 e 1,34 respectivamente.

Bioensaios com as populações de $S$. oryzae (Tabela II) mostraram que a população $A$, proveniente de criação de laboratório de origem incerta (Fig. 1E), apresentou $\mathrm{CL}_{50}$ de 1,209 (concentração de 1,7\% de deltametrina), significativamente diferente da população $B$, também de laboratório, mas de procedência diferente daquela da população A (Fig. 1F), cuja

\section{R. dominica}

\section{O. surinamensis}

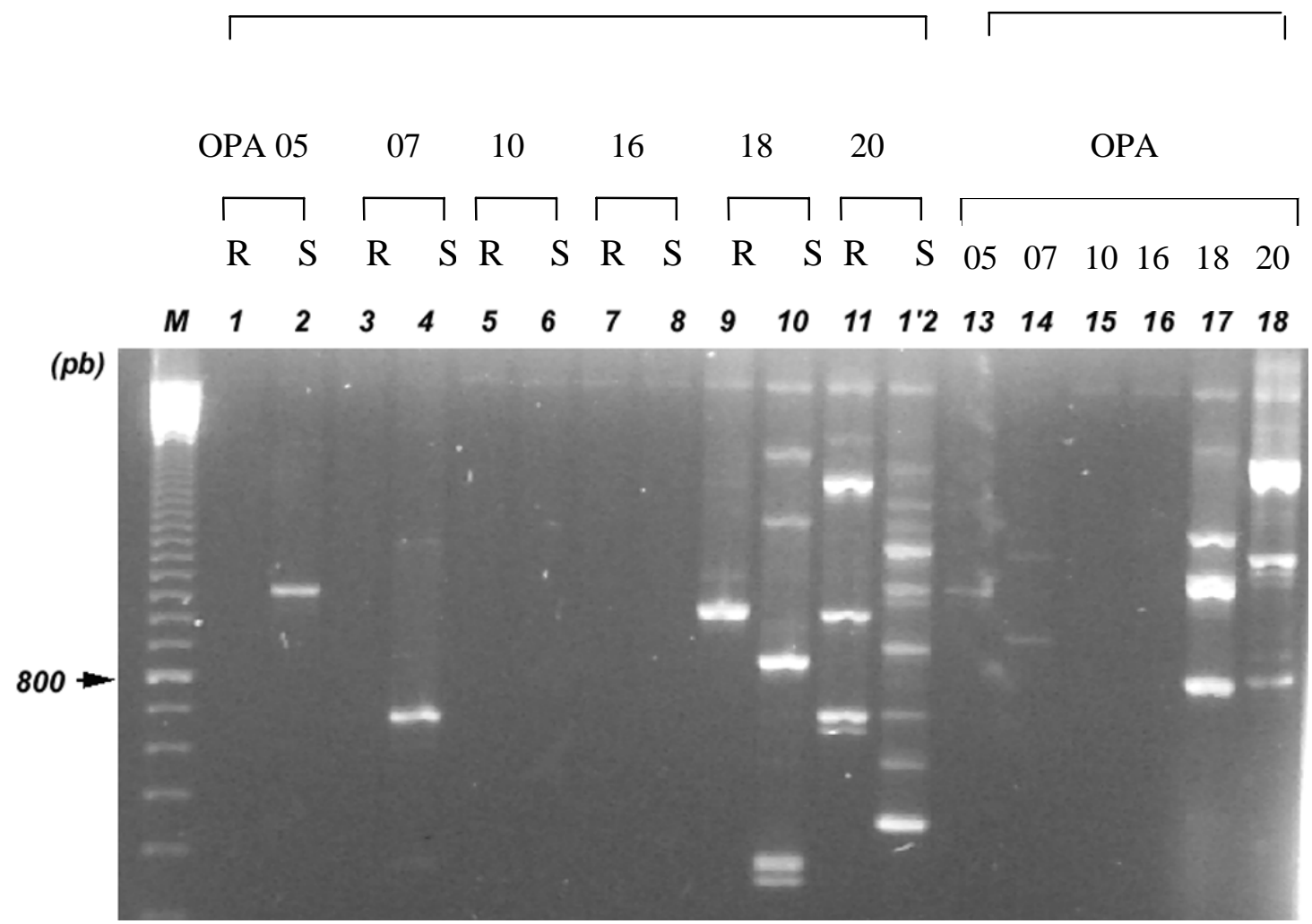

Fig. 2. Padrão de fragmentos de DNA de Rhyzopertha dominica BR12, considerada resistente (R); BR4 suscetível (S) e Oryzaephilus surinamensis amplificados por PCR-RAPD com os primers indicados; marcador com 100 pb (M). 
$\mathrm{CL}_{50}$ foi 0,1315 (1\% de deltametrina). Esses resultados indicam que a população B é mais suscetível ao inseticida, pois, foi utilizada apenas a metade da concentração da população A para matar $50 \%$ da população, sendo que o FR foi de 9,2. Infelizmente, não se tem registro da origem dessas duas populações, informação essa que poderia auxiliar na interpretação dos resultados como, por exemplo, uma diferença de pressão de seleção à qual teriam sido submetidas.

Bioensaios com as populações de $R$. dominica (Tabela II) provenientes da Embrapa-Trigo, Passo Fundo-RS, indicaram que a população de $R$. dominica BR12 (Fig. 1G), com $\mathrm{CL}_{50}$ de 0,4883 , apresenta diferença significativa com a população de R. dominica BR4 (Fig. $1 \mathrm{H}$ ) com $\mathrm{CL}_{50}$ de 0,2212. Esta última apresentou maior suscetibilidade ao inseticida mesmo a uma concentração menor do que utilizada na população BR12, confirmando o histórico de resistência dessas raças, as quais foram caracterizadas e previamente testadas na Embrapa-Trigo (BECKEL 2000). O FR da raça BR12 foi 2,2 vezes maior que o da raça BR4. Este resultado diferiu consideravelmente do valor ( $F R=873,2$ ) encontrado por BECKEL (2000). As possíveis razões pelas quais a população de $R$. dominica BR12, tida como resistente, não alcançou esse status nos bioensaios, podem ser: o bioensaio não foi capaz de evidenciar a magnitude da resistência desta população; a resistência anteriormente detectada pode ser instável ou não se expressar porque as populações deixaram de sofrer pressão seletiva sendo que o baixo b confirma-a como uma população heterogênea; ou pode ter havido contaminação com a entrada de migrantes suscetíveis.
O bioensaio realizado com $O$. surinamensis (Tabela II) mostrou uma $\mathrm{CL}_{50}$ de 0,1966 (Figura 1-I), com as menores concentrações utilizadas nos bioensaios, ficando no mesmo nível de suscetibilidade das populações suscetíveis das espécies de Sitophilus. Não foi possível obter outra população da espécie para determinar o fator de resistência dessa amostra.

\section{Ensaios com Marcadores Moleculares}

Os métodos utilizados para a preservação do material (in vivo, etanol a $70 \%$ temperatura ambiente e congelados $-18^{\circ} \mathrm{C}$ ) mostraram-se eficientes para a preservação e extração, por até oito meses, sem interferir na quantidade, qualidade e nas reações de amplificação do DNA. As amostras apresentaram quantidade e qualidade satisfatórias de DNA para as análises posteriores, significando que não houve degradação do material.

A Fig. 2 apresenta as bandas de DNA para $R$. dominica e O. surinamensis. Os primers OPA-05 e OPA-07 amplificaram, respectivamente, uma banda com $1.150 \mathrm{pb}$ e $700 \mathrm{pb}$, ambas para a população suscetível de $R$. dominica (amostras 2 e 4), e nenhum fragmento para a população resistente (amostras $1 \mathrm{e}$ 3). Os primers OPA-18 e OPA-20 amplificaram uma série de fragmentos entre 300 e $2000 \mathrm{pb}$ para as populações resistentes e suscetíveis de $R$. dominica (amostras 9 a 12), sendo que ambos os primers indicam a possibilidade de existência de variabilidade genética entre estas populações. Os primers OPA10 e OPA-16 (amostras 5 a 8) não amplificaram nenhum fragmento de DNA.

Para O. surinamensis, apenas os primers OPA-18 e OPA-20 amplificaram fragmentos de DNA, sendo que os demais não

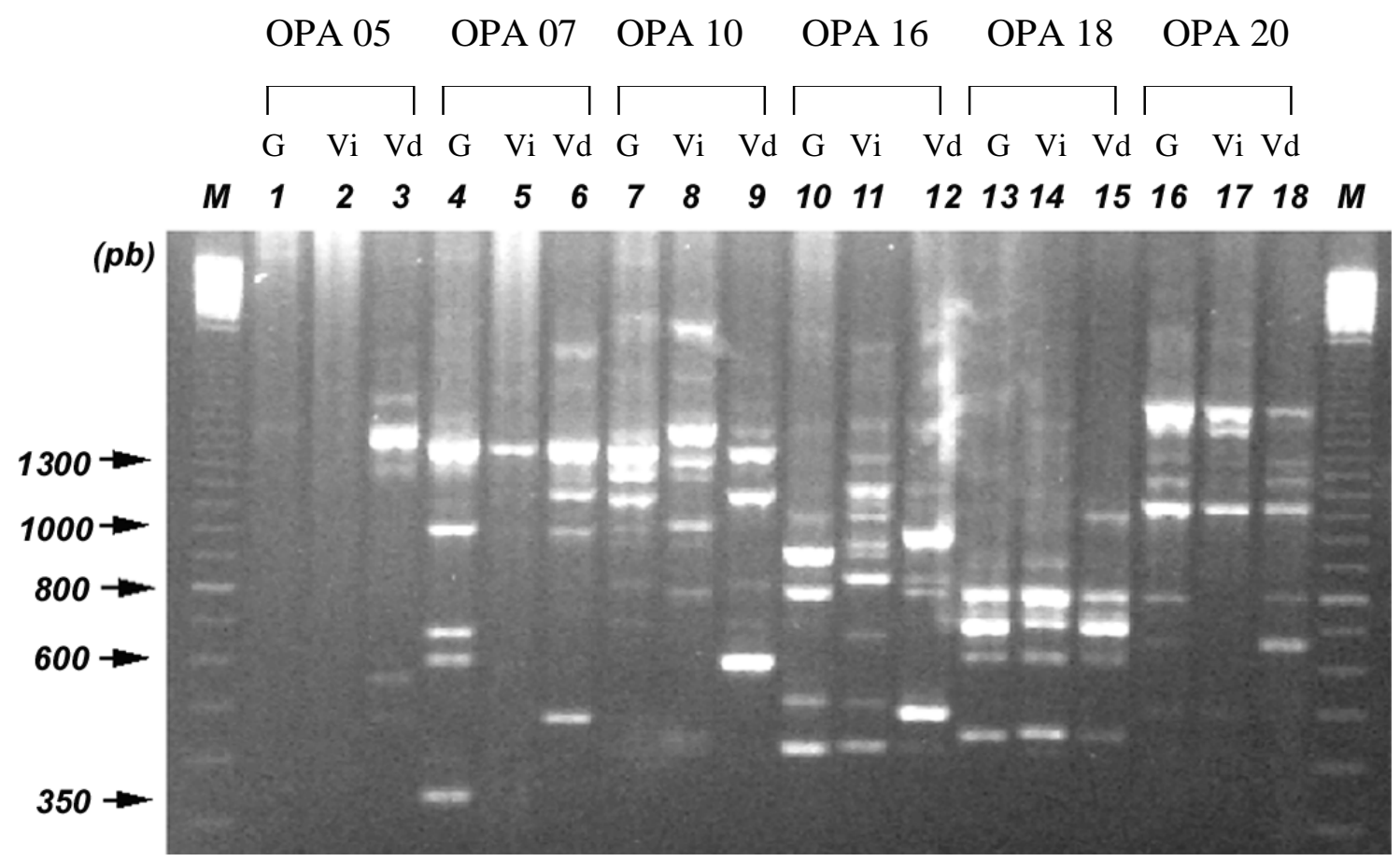

Fig. 3. Padrão de fragmentos de DNA de Sitophilus zeamais Guarapuava (G), Viçosa (Vi) e Videira (Vd) amplificados por PCR-RAPD com os primers indicados; marcador com $100 \mathrm{pb}(\mathrm{M})$. 
amplificaram ou, como no caso de OPA-05, os fragmentos amplificados foram pouco visíveis (amostras 13 a 16).

Os resultados de RAPD para $S$. zeamais estão apresentados na Fig. 3. Observa-se que os primers OPA-07, OPA-10 e OPA16 (amostras 4 a 12) amplificaram diversos fragmentos polimórficos para as populações de $S$. zeamais procedentes de Guarapuava, Viçosa e Videira. Os diferentes padrões de bandas apresentados por cada um desses primers, para cada população de $S$. zeamais, embora tenha sido utilizado apenas um espécime de cada local, indicam a possibilidade de uma ocorrência de variabilidade genética entre essas populações. O primer OPA05 (amostras 1 a 3) não amplificou satisfatoriamente os fragmentos de DNA das amostras das três populações, não permitindo qualquer inferência. Os primers OPA-18 e OPA-20 (amostras 13 a 18), apresentaram padrões semelhantes para as três populações caracterizando falta de variabilidade entre as populações.

O RAPD é considerado um marcador do tipo dominante, assim se a característica é monogênica e recessiva, o marcador pode ser encontrado no heterozigoto, que não é resistente, mas, pelo perfil das bandas, poderia ser considerado como tal. Assim, é necessário testar um grande número de amostras e primers para detectar marcadores úteis para detectar genes responsáveis pela resistência desses insetos a inseticidas.

\section{CONCLUSÃO}

Os bioensaios indicam que existem populações de $S$. zeamais, $S$. oryzae e $R$. dominica com fatores de resistência que podem afetar sua resposta à aplicação de deltametrina.

Amostras de $S$. zeamais, $S$. oryzae, $R$. dominica e $O$. surinamensis podem ser utilizadas in vivo, preservadas em etanol a $70 \%$ ou congeladas a $-18^{\circ} \mathrm{C}$ por até oito meses, sem alterar a qualidade do DNA para os ensaios de PCR-RAPD.

As análises PCR-RAPD revelam bandas que mostram variabilidade intraespecífica das populações, indicando que esta técnica pode ser utilizada para a detecção da resistência/ suscetibilidade, porém, ficou evidente que um número maior de primers e populações precisam ser testados para se chegar a resultados mais definitivos quanto à marcação da resistência/ suscetibilidade. A utilização de primers específicos pode oferecer suporte para os resultados de bioensaios que, em conjunto, representam uma ferramenta precisa e útil para programas de manejo da resistência de insetos de produtos armazenados.

Agradecimentos. Ao Dr. Alfredo Otávio R. de Carvalho e Dr. Luiz Gonzaga Esteves Vieira, do Instituto Agronômico do Paraná (IAPAR) Londrina, PR, pelo apoio técnico e cessão do laboratório para os testes com marcadores moleculares; à doutoranda Helenara dos Santos Beckel e ao Dr. Irineu Lorini da Embrapa - Trigo, Passo Fundo, RS, pelo envio de insetos e apoio nas análises dos bioensaios; à Perdigão Agroindustrial S/A, pelo fornecimento de grãos com insetos para os bioensaios; ao CNPq, pelas bolsas de iniciação científica e de produtividade em pesquisa.

\section{REFERÊNCIAS}

Beckel, H. S. 2000. Comportamento de Rhyzopertha dominica (F.) (Coleoptera: Bostrychidae) em relação à resistência ao inseticida deltamethrin. Dissertação de Mestrado. Universidade Federal do Paraná, Curitiba, 63 p.

Brown, A. W. A. 1958. Insecticide resistance in arthropods. Geneva, World Health Organization, 148 p.

Cheung, W. Y.; N. Hubert \& B. S. Landry. 1993. A simple and rapid microextraction method for plant, animal, and insect suitable for RAPD e other PCR analyses. PCR Methods and Applications 3: 69-70.

Collins, P. J. 1990. A new resistance to pyrethroids in Tribolium castaneum (Herbst.) Pesticid in Science 28: 101-115.

Collins, P. J.; H. A. Rose \& M. Wegecsanyi. 1992. Enzyme activity in strains of the sawtoothed grain beetle (Coleoptera: Cucujidae) differentially resistant to fenitrothion, malathion and chlorpyrifosmethyl. Journal of Economic Entomology 85: 1571-1575.

Crawley, M. J. 1993. Glim for ecologists. Oxford, Blackwell Scientific Publications, Ed. United Kingdom, 379 p.

FAO 1974. Recommended methods for the detection and measurement of resistance of agricultural pest to pesticides. Method for adults of some major pests of stored cereals with malathion or lindane. FAO Method 15. FAO Plant Protection 22: 127-137.

Georghiou, G. P. 1972. The evolution of resistance to pesticides. Annual Review of Ecology and Systematics 3: 133-168.

Guedes, R. N. C. 1993. Detecção e herança de resistência ao DDT e piretróides em Sitophilus zeamais Motschulsky (Coleoptera: Curculionidae). Tese de Mestrado, Universidade Federal de Viçosa, Viçosa, $67 \mathrm{p}$.

Guedes, R. N. C.; S. Kambhampati; B. A. Dover \& K. Y. Zhu. 1997. Biochemical mechanisms of organophosphate resistance in Rhyzopertha dominica (Coleoptera: Bostrichidae) populations from the United State and Brazil. Bulletin of Entomological Research 87: 581-586.

LORINI, I. 1998. Controle integrado de pragas de grãos armazenados. Passo Fundo, Embrapa-CNPT (Embrapa-CNPT Documentos, 48), $52 \mathrm{p}$.

Pacheco, I. A.; M. R. SARTori \& S. Bolonhesi. 1991. Resistance to malathion, pirimiphos-methyl and fenitrothion in Coleoptera from stored grains, p.1029-1037. In: Proceedings of the $5^{\text {th }}$ International Working Conference on Stored-Product Protection. Bordeaux, INRA/ SPDV.

Ribeiro, B. M.; R. N. C. Guedes; E. E. Oliveira \& J. P. Santos. 2003 Insecticide resistance and synergism in Brazilian populations of Sitophilus zeamais (Coleoptera: Curculionidae). Journal of Stored Products Research 39: 21-31.

Roush, R. T. 1989. Designing resistance management programs: how can you choose? Pesticide in Science 26: 423-441.

Sartori, M. R.; I. A. Pacheco \& R. M. G. Vilar. 1991. Resistance to phosphin in stored grain insects in Brazil, p. 1041-1050. In: Proceedings of the $5^{\text {th }}$ International Working Conference on Stored-Product Protection. Bordeaux, INRA/SPDV.

Sмітн, R. F. 1970. Pesticides: their use and limitations in pest management, p. 103-113 In: Concepts of pest management. Raleigh, North Carolina State University.

Subramanyam, Bh. \& D. W. Hagstrum. 1996. Resistance measure and management, p. 331-397. In: Bh. Subramanyam \& D. W. Hagstrum (Eds.). Integrated management of insects in stored products. New York, Marcel Dekker Inc.

Subramanyam, Bh.; P. K. Harein \& L. K. CutKomp. 1989. Organophosphate resistance in adults of red flour beetle (Coleoptera: Tenebrionidae) and sawtoothed grain beetle (Coleoptera: Cucujidae) infesting barley stored on farms in Minnesota. Journal of Economic Entomology 82: 989-995.

TABASHNIK, B. E. 1989. Managing resistance with multiple pesticide tactics: theory, evidence, and recommendations. Journal of Economic Entomology 82: 1263-1269. 